\title{
Occupational and Personal Determinants of Musculoskeletal Disorders among Urban Taxi Drivers in Ghana
}

\author{
J. K. Abledu, ${ }^{1}$ E. B. Offei, ${ }^{1}$ and G. K. Abledu ${ }^{2}$ \\ ${ }^{1}$ School of Veterinary Medicine, University of Ghana, Accra, Ghana \\ ${ }^{2}$ Faculty of Applied Science and Technology, Koforidua Polytechnic, Koforidua, Ghana
}

Correspondence should be addressed to J. K. Abledu; jkabledu@gmail.com

Received 13 March 2014; Revised 17 May 2014; Accepted 9 June 2014; Published 14 August 2014

Academic Editor: Karen Søgaard

Copyright (C) 2014 J. K. Abledu et al. This is an open access article distributed under the Creative Commons Attribution License, which permits unrestricted use, distribution, and reproduction in any medium, provided the original work is properly cited.

\begin{abstract}
Background. There is a lack of epidemiological data on musculoskeletal disorders (MSDs) among occupational drivers in Ghana. The present study seeks to estimate the prevalence, body distribution, and occupational and personal determinants of MSDs in a sample of taxi drivers in the Accra Metropolis of Ghana. Methods. A total of 210 participants were enrolled in this cross-sectional study. All the participants were evaluated by using a semistructured questionnaire and the standardized Nordic Musculoskeletal Disorder Questionnaire. Results. The estimated prevalence of MSDs was 70.5\%. The prevalence of the various MSD domains was as follows: lower back pain (34.3\%), upper back pain (16.7\%), neck pain (15.2\%), shoulder pain (11.0\%), knee pain (10.0\%), hip/thigh pain (2.9\%), elbow pain (4.8\%), ankle/feet pain (2.4\%), and wrist/hand pain (1.9\%). Multiple logistic regression analysis of the data showed that participants who were employee drivers, drove taxi more than 12 hours per day or at least 5 days per week, perceived their job as stressful, and were dissatisfied with their job were at a greater risk of developing MSDs. Conclusions. These findings call for preventive strategies and safety guidelines in order to reduce the incidence of MSDs among urban taxi drivers in Ghana.
\end{abstract}

\section{Background}

Taxis play a critical role in Ghana's urban transport system. They are typically the most accessible form of transport anytime of the day, almost anywhere, every day of the year [1] but the nature of work in the taxi industry is potentially hazardous because of the many risks involved which can vary in severity from verbal abuse, violent assault to homicide [2-5]. According to Copsey and Taylor [6], the main risks include physical risks (road accidents, vibrations, manual handling of loads, and long sitting position), chemical and biological risks (urban pollution), psychosocial risks caused by stress and violence, and risks due to individual behavior such as smoking and use of stimulants. A number of these factors are said to increase taxi drivers' risk of developing musculoskeletal disorders [5, 7-10].

Musculoskeletal disorders (MSDs) cover a wide range of conditions (e.g., tendonitis, tenosynovitis, epicondylitis, bursitis, carpal tunnel syndrome, sciatica, osteoarthrosis, myalgia, low back pain, and other idiopathic pain syndromes) that cause inflammation and degeneration of the musculoskeletal system and neurovascular structures [11]. They are a major public health problem worldwide, affect the quality of life [12], and cause substantial morbidity and disability [13] with consequent economic loss in terms of sickness absence and cost of treatment [14]. MSDs are multifactorial in terms of aetiology; the risk factors include awkward posture, manual handling, heavy lifting, strenuous tasks, and repetitive activities, while demographics, workload, and psychosocial factors are known to play parts in the pathogenesis [14].

The fact that professional driving is associated with MSDs is supported by epidemiological studies among drivers of different types of vehicle including truck drivers $[15,16]$, agricultural truck drivers [17], forklift drivers [18, 19], bus drivers [20], and taxi drivers $[5,7,9,10]$. Professional taxi drivers, particularly those who work in urban cities, are said to be at increased risk of developing MSDs because of the relatively confined space in the taxi cabs as well as the long hours spent behind the wheel [9]. 
Despite considerable epidemiological evidence that occupational driving is associated with increased risk of MSDs, there has been no empirical research on MSDs among occupational drivers in Ghana to date. The present study, therefore, seeks to estimate the one-year prevalence, body distribution, and personal and occupational determinants of MSDs among a sample of taxi drivers in the Accra Metropolis of Ghana.

\section{Methods}

2.1. Participants. This cross-sectional study was conducted between November 2013 and January 2014 at various taxi ranks in Accra, the largest and capital city of Ghana. All the participants recruited in the study were male drivers with at least one year experience of driving taxi, who had no history of traumatic road or work accidents and aged 18 years or more.

2.2. Procedure. The participants in this study were contacted while waiting at the taxi rank. All consented participants were evaluated using a three-part semistructured questionnaire that included the standardized Nordic Musculoskeletal Questionnaire (NMQ). Participants who could neither read nor write English were assessed (at interview) using a validated and standardized translation of the questionnaire (in the local Ghanaian language). In all, a total of 300 drivers were contacted.

The first part of the questionnaire collected data on participants' sociodemographic information (age, marital status, religion, and education) and behavioural and lifestyle activities (alcohol consumption, smoking, and physical exercise). Part two of the questionnaire assessed occupational factors including taxi ownership (owner or employee driver), driving time profile (number of years of driving taxi, total driving hours per day, and number of days per week of driving), physical exposure (load handling and lifting at work), sleeping breaks in cars, and psychological factors such as perceived job stress and job satisfaction. The third part of the questionnaire mainly assessed the musculoskeletal health of drivers using the standardized Nordic Musculoskeletal Questionnaire (NMQ).

\subsection{Nordic Musculoskeletal Questionnaire (NMQ). The NMQ} [21] is a validated [21-23] tool and consists of a general questionnaire for analysis of the point prevalence (7 days), period prevalence (12 months), and severity or disability (effect on normal activities over the last 12 months) of musculoskeletal trouble in different body areas such as neck, shoulders, elbows, wrists/hands, upper back, lower back, hips/thighs, knees, and ankles/feet. The NMQ was chosen because it is standardized, widely accepted, easy to administer and time/cost saving in terms of constructing and piloting a new questionnaire.

2.4. Statistical Analysis. The data were categorized and presented as proportions. Univariate logistic regression was used to obtain estimates of the prevalence odds ratio (POR) of independent factors associated with MSDs. Multiple logistic regression (simultaneous variable entry) was used to obtain estimates of the POR adjusted for the effects of all confounding variables. All statistical analyses were performed using Statistical Package for Social Sciences for Windows, version 20 (IBM Corporation, USA). Statistical significance for all tests was set at $5 \%$ alpha level.

\section{Results}

3.1. Response Rate, Demographics, and Personal and Occupational Factors. Out of the 300 taxi drivers contacted for the study, 45 denied participation, 26 had to terminate the study when passengers arrived, and 19 returned incomplete questionnaire, leaving 210 complete and evaluable questionnaires, indicating a response rate of $70.0 \%$. Participants' age ranged from 23 to 61 years with mean \pm standard deviation of $32.1 \pm$ 8.7 years. The average number of years of driving taxi, driving time (in hours) per day, and driving time (in days) per week were $4.2 \pm 3.3$ years, $11.0 \pm 2.7$ hours, and $5.1 \pm 1.2$ days, respectively.

The sociodemographic characteristics of the subjects are presented in Table 1. In all, 63.6\% (134 out of the 210) respondents were married whereas the remaining $35.4 \%$ were single; a majority of them were Christians (74.4\%) as were those who had high school education (60.5\%) with only $10.5 \%$ attaining above senior high school education. More than half $(57.7 \%)$ of the respondents took alcoholic beverages, $6.7 \%$ smoked cigarettes, and $25.8 \%$ engaged in some form of sports activities. Generally, the respondents fell into two main categories: taxi owners (35.4\%) and employee drivers (64.6\%); 73.2\% respondents often engaged in load handling and lifting activities at work while $29.4 \%$ took sleeping breaks in their taxis. A majority $(84.7 \%)$ of the respondents perceived their job as stressful and about one-third (28.7\%) of the participants were dissatisfied with their current job.

3.2. Musculoskeletal Disorders-NMQ. The estimated oneyear prevalence of MSDs within the participants was 70.5\% (i.e., 148 out of 210). The prevalence of the various MSD domains was lower back pain (72 out of 210, 34.3\%), upper back pain (35 out of $210,16.7 \%$ ), neck pain (32 out of 210 , $15.2 \%$ ), shoulder pain (23 out of $210,11.0 \%$ ), knee pain (21 out of $210,10.0 \%)$, hip/thigh pain (6 out of $210,2.9 \%$ ), elbow pain (10 out of $210,4.8 \%$ ), ankle/feet pain (5 out of $210,2.4 \%$ ), and wrist/hand pain (4 out of 210, 1.9\%).

3.3. Determinants of MSDs. The association between MSDs and different personal (demographic) and occupational variables is reported in Tables 2 and 3, respectively. Lack of sports activity $(\mathrm{OR}=3.2 ; 95 \% \mathrm{CI}=1.4-3.8 ; P<0.001)$, being an employee driver $(\mathrm{OR}=2.7 ; 95 \% \mathrm{CI}=2.0-4.2 ; P<0.01)$, driving time $>12$ hours/day $(\mathrm{OR}=2.6 ; 95 \% \mathrm{CI}=1.8-3.5$; $P<0.01)$, and driving 5-7 days per week (OR $=2.9 ; 95 \%$ $\mathrm{CI}=2.1-7.6 ; P<0.001)$ were the significant variables that increased the odds of MSDs in the univariate analysis. Also, those who perceived their job as stressful were 3 times more 
TABLE 1: Sociodemographic characteristics of the participants $(n=$ 210).

\begin{tabular}{|c|c|c|}
\hline Characteristic & $n$ & $\%$ \\
\hline \multicolumn{3}{|l|}{ Marital status } \\
\hline Married & 134 & 63.6 \\
\hline Single & 76 & 36.4 \\
\hline \multicolumn{3}{|l|}{ Education } \\
\hline Below senior high school & 61 & 28.9 \\
\hline Senior high school & 127 & 60.5 \\
\hline Above senior high school & 22 & 10.5 \\
\hline \multicolumn{3}{|l|}{ Religion } \\
\hline Christian & 156 & 74.4 \\
\hline Moslem & 45 & 21.5 \\
\hline Others & 9 & 4.1 \\
\hline \multicolumn{3}{|l|}{ Taxi ownership } \\
\hline Owner & 74 & 35.4 \\
\hline Employee & 136 & 64.6 \\
\hline \multicolumn{3}{|l|}{ Perceived job stress } \\
\hline None & 32 & 15.3 \\
\hline Moderate to severe & 178 & 84.7 \\
\hline \multicolumn{3}{|l|}{ Sleeping breaks in car } \\
\hline Yes & 62 & 29.4 \\
\hline No & 148 & 70.6 \\
\hline \multicolumn{3}{|l|}{ Job satisfaction } \\
\hline Satisfied & 150 & 71.3 \\
\hline Dissatisfied & 60 & 28.7 \\
\hline \multicolumn{3}{|l|}{ Alcohol } \\
\hline Yes & 89 & 42.3 \\
\hline No & 121 & 57.7 \\
\hline \multicolumn{3}{|l|}{ Smoking } \\
\hline Yes & 14 & 6.7 \\
\hline No & 196 & 93.3 \\
\hline \multicolumn{3}{|l|}{ Regular sports activity } \\
\hline yes & 54 & 25.8 \\
\hline No & 156 & 74.2 \\
\hline \multicolumn{3}{|c|}{ Load handling and lifting at work } \\
\hline Yes & 154 & 73.2 \\
\hline No & 56 & 26.8 \\
\hline
\end{tabular}

Percentages may not sum up to exactly 100 because of approximations.

likely to have MSDs as compared to those who did not (OR $=2.7 ; 95 \% \mathrm{CI}=1.8-3.9 ; P<0.01$ ), and those who were dissatisfied with their job were twice more likely to have MSDs than those who were satisfied with their job $(\mathrm{OR}=2.3$; $95 \% \mathrm{CI}=1.6-4.0 ; P<0.05)$.

After adjusting for possible confounding variables in multivariate analysis, the significant factors associated with MSDs were as follows: being an employee driver, driving time $>12$ hours per day, driving 5-7 days per week, self-perceived job stress, and job dissatisfaction (Table 3).

\section{Discussion}

MSDs are highly prevalent among drivers, varying between $53 \%$ and $91 \%$ in different parts of the world $[5,15,24-$ 26]. However, there has been no empirical study on MSDs
TABLE 2: Personal factors associated with MSDs among the participants $(n=210)$.

\begin{tabular}{|c|c|c|}
\hline Parameter & OR $(95 \%$ CI $)$ & $\mathrm{aOR}(95 \% \mathrm{CI})$ \\
\hline \multicolumn{3}{|l|}{ Age (years) } \\
\hline$<45$ & $0.6(0.2-2.2)$ & - \\
\hline $46-55$ & 1 & - \\
\hline$>55$ & $0.7(0.4-2.8)$ & - \\
\hline \multicolumn{3}{|l|}{ Marital status } \\
\hline Married & 1 & - \\
\hline Single & $2.3(1.9-4.8)$ & - \\
\hline \multicolumn{3}{|l|}{ Education } \\
\hline Below senior high school & $0.4(0.1-1.9)$ & - \\
\hline Senior high school & 1 & - \\
\hline Above senior high school & $0.5(0.2-2.1)$ & - \\
\hline \multicolumn{3}{|l|}{ Religion } \\
\hline Christian & $2.3(1.7-4.3)$ & - \\
\hline Islam & $2.6(1.8-4.5)$ & - \\
\hline Others & 1 & - \\
\hline \multicolumn{3}{|l|}{ Alcohol } \\
\hline No & 1 & - \\
\hline Yes & $2.7(2.1-3.5)$ & - \\
\hline \multicolumn{3}{|l|}{ Smoking } \\
\hline No & 1 & - \\
\hline Yes & $0.8(0.1-3.9)$ & - \\
\hline \multicolumn{3}{|l|}{ Regular sports activity } \\
\hline No & $3.2(1.4-3.8)^{* * *}$ & $0.8(0.3-1.9)$ \\
\hline Yes & 1 & 1 \\
\hline
\end{tabular}

among occupational drivers in Ghana to date, hence the need for the present study. The estimated period prevalence of MSDs (70.5\%) in this study is consistent with the worldwide prevalence range and the hypothesis that urban taxi drivers are at increased risk of developing MSDs. Also, the observed prevalence and pattern of distribution of MSDs in the different body regions suggest a somewhat degree of diversity in the musculoskeletal pain reported by the participants. This diversity could, in part, be due to individual differences in the modulators of self-reported pain which include genetic composition, psychological status, and economic and sociocultural factors [27].

Low back pain (LBP) was the commonest symptom, occurring in $34.3 \%$ of the drivers. Whereas this prevalence rate is lower than the prevalence range $(45.8 \%-59 \%)$ reported among Caucasians $[5,7,9,28]$, it is similar to the $30.66 \%$ rate reported among Nigerian taxicab drivers with similar sociocultural characteristics [29].

Increased odds of developing MSDs with increased duration of driving were observed among the participants in this study (i.e., driving $>12$ hours/day and at least 5 days/week was significantly associated with increased risk of MSDs). Prolonged driving (sitting) or static posture in a relatively confined and vibrating taxicab environment (that offers little room for flexing and movement of the limbs) can cause 
TABLE 3: Occupational factors associated with MSDs among the participants $(n=210)$.

\begin{tabular}{|c|c|c|}
\hline Parameter & OR $(95 \% \mathrm{CI})$ & aOR $(95 \% \mathrm{CI})$ \\
\hline \multicolumn{3}{|l|}{ Type of taxi driver } \\
\hline Owner & 1 & 1 \\
\hline Employee & $2.7(2.0-4.2)^{* *}$ & $2.4(1.9-3.6)^{*}$ \\
\hline \multicolumn{3}{|c|}{ Number of years of driving } \\
\hline$<6$ & $0.4(0.1-2.7)$ & - \\
\hline $6-10$ & 1 & - \\
\hline$>10$ & $0.7(0.2-2.1)$ & - \\
\hline \multicolumn{3}{|c|}{ Driving time per day (hours) } \\
\hline$<10$ & $0.5(0.1-1.9)$ & $0.3(0.1-1.2)$ \\
\hline $10-12$ & 1 & 1 \\
\hline$>12$ & $2.6(1.8-3.5)^{* *}$ & $1.7(1.1-2.2)^{*}$ \\
\hline \multicolumn{3}{|c|}{ Driving time per week (days) } \\
\hline$<5$ & 1 & 1 \\
\hline $5-7$ & $2.9(2.1-7.6)^{* * *}$ & $2.1(1.5-4.1)^{* * *}$ \\
\hline \multicolumn{3}{|l|}{ Perceived job stress } \\
\hline None & 1 & 1 \\
\hline Moderate to severe & $2.7(1.8-3.9)^{* *}$ & $2.3(1.5-3.0)^{* *}$ \\
\hline \multicolumn{3}{|l|}{ Sleeping breaks in car } \\
\hline No & 1 & - \\
\hline Yes & $2.4(1.8-11.9)$ & - \\
\hline \multicolumn{3}{|l|}{ Job satisfaction } \\
\hline Satisfied & 1 & 1 \\
\hline Dissatisfied & $2.3(1.6-4.0)^{*}$ & $2.0(1.3-3.6)^{*}$ \\
\hline \multicolumn{3}{|c|}{ Load handling and lifting at work } \\
\hline No & 1 & 1 \\
\hline Yes & $2.4(1.4-5.7)$ & - \\
\hline
\end{tabular}

OR: odds ratio; aOR: adjusted odds ratio; CI: confidence interval; ${ }^{*} P<0.05$; ${ }^{* *} P<0.01 ;{ }^{* * *} P<0.001$.

postural strain on the musculoskeletal system. This can be uncomfortable and stressing and thus increase susceptibility to musculoskeletal injury/pain. An association between MSDs and daily or weekly driving duration is supported by several studies. For instance, a study [10] among taxi drivers in Taipei city of Taiwan found that driving more than 10 hours/day increased the risk of knee pain in this population. Chen et al. [9] also found that driving taxi more than 4 hours/day was associated with a greater risk of low back pain. Driving $>71$ hours/week [5] and $>20$ hours/week [24] was also found to be associated with high frequency of low back pain.

From this study, employee drivers were more likely to develop MSDs than owner drivers presumably because they (employee-drivers) have less control over their working hours. Contrary to reports in the literature $[5,9,30]$ age, number of years of driving, alcohol consumption, smoking, taking sleeping breaks in the taxi, and work-related activities such as load handling and lifting at work were not associated with MSDs in the present study. This could be due to methodological, sampling, or population differences.

In this study, psychosocial factors such as self-perceived job stress and job dissatisfaction were significantly associated with MSDs even after adjusting for possible confounders in multivariate analysis. The exact role of psychosocial factors in the development of MSDs is poorly understood; however, they are known to cause psychosocial stress. Psychosocial stress can cause muscle tension, mechanical strain of the spinal cord, and fatigue, all of which could lead to traumatic injury [30], hence MSDs. Several studies [9, 10] have identified self-perceived job stress, job dissatisfaction, and mental health as important determinants of musculoskeletal discomfort of urban taxi drivers.

Lack of sports activities was associated with increased odds of MSDs in this study; however, this observation diminished after adjusting for potential confounders including driving duration, ownership of taxi, self-perceived job stress, and job dissatisfaction. Randomized clinical trials have shown that physical activity has direct effect on physical fitness [31]. That said, regular physical activity (according to advocates in USA) would prevent communicable diseases, decrease all-cause mortality, and promote health [32]. However, whether physical activity is beneficial to musculoskeletal health is unclear. Some studies [13, 33] have indicated favourable relation between the frequency of leisure time sports activity and MSDs; others $[32,34]$ found no association between the duo while Miranda et al. [35] reported adverse effects. In their study, Miranda et al. [35] found that individuals who engaged in active walking had more sciatic pain; active volleyball players had more shoulder pain while those who actively practiced trekking had more knee pain than those who practiced these activities less. Physical activityrelated injuries are common and it is possible that these injuries were included in self-reported MSDs in this study. Randomized clinical trials on the effects of physical activity on MSDs are required.

\section{Conclusions}

The estimated one-year prevalence of MSDs within the taxi drivers was $70.5 \%$. Taxi drivers have a high prevalence of MSDs that is dependent on ownership of taxi, daily and weekly driving duration, self-perception of job stress, and job satisfaction. These findings call for preventive strategies and safety guidelines in order to reduce the incidence of MSDs of urban taxi drivers in Ghana. This cross-sectional study provides the baseline for elaborative studies in the future.

\section{Conflict of Interests}

The authors declare that there is no conflict of interests regarding the publication of this paper.

\section{Acknowledgments}

The authors are grateful to the participants for their contributions and all research assistants who were part of the data collection process. 


\section{References}

[1] M. Sheahan and P. Smith, "Deviance and marginal occupations: the case of taxi drivers," Deviant Behavior, vol. 24, no. 5, pp. 449466, 2003.

[2] M. A. Machin and J. M. D. de Souza, "Predicting health outcomes and safety behaviour in taxi drivers," Transportation Research F: Traffic Psychology and Behaviour, vol. 7, no. 4-5, pp. 257-270, 2004.

[3] G. Warchol, "Workplace violence," Age, vol. 17, pp. 18-24, 1998.

[4] C. Mayhew, Violent Assaults on Taxi Drivers: Incidence Patterns and Risk Factors, Australian Institute of Criminology, 2000.

[5] R. K. Raanaas and D. Anderson, "A questionnaire survey of Norwegian taxi drivers' musculoskeletal health, and work-related risk factors," International Journal of Industrial Ergonomics, vol. 38, no. 3-4, pp. 280-290, 2008.

[6] S. Copsey and T. N. Taylor, Taxi Drivers'Safety and Health: A European Review of Good Practice Guidelines, European Agency for Safety and Health at Work, 2010.

[7] M. Funakoshi, K. Taoda, H. Tsujimura, and K. Nishiyama, "Measurement of whole-body vibration in taxi drivers," Journal of Occupational Health, vol. 46, no. 2, pp. 119-124, 2004.

[8] J.-C. Chen, J. T. Dennerlein, C.-C. Chang, W.-R. Chang, and D. C. Christiani, "Seat inclination, use of lumbar support and lowback pain of taxi drivers," Scandinavian Journal of Work, Environment \& Health, vol. 31, no. 4, pp. 258-265, 2005.

[9] J.-C. Chen, W.-W. Chang, and D. Christiani, "Occupational factors associated with low back pain in urban taxi drivers," Occupational Medicine, vol. 55, no. 7, pp. 535-540, 2005.

[10] J.-C. Chen, J. T. Dennerlein, T. Shih et al., "Knee pain and driving duration: a secondary analysis of the Taxi Drivers' Health Study," American Journal of Public Health, vol. 94, no. 4, pp. 575-581, 2004.

[11] L. Punnett and D. H. Wegman, "Work-related musculoskeletal disorders: the epidemiologic evidence and the debate," Journal of Electromyography and Kinesiology, vol. 14, no. 1, pp. 13-23, 2004.

[12] C. H. Roux, F. Guillemin, S. Boini et al., "Impact of musculoskeletal disorders on quality of life: an inception cohort study," Annals of the Rheumatic Diseases, vol. 64, no. 4, pp. 606-611, 2005.

[13] T. Morken, T. Riise, B. Moen et al., "Low back pain and widespread pain predict sickness absence among industrial workers," BMC Musculoskeletal Disorders, vol. 4, article 1, 2003.

[14] J. Abledu and G. Abledu, "Multiple logistic regression analysis of predictors of musculoskeletal disorders and disability among bank workers in Kumasi, Ghana," Journal of Ergonomics, vol. 2, article 2, 2012.

[15] M. J. M. Robb and N. J. Mansfield, "Self-reported musculoskeletal problems amongst professional truck drivers," Ergonomics, vol. 50, no. 6, pp. 814-827, 2007.

[16] M. Massaccesi, A. Pagnotta, A. Soccetti, M. Masali, C. Masiero, and F. Greco, "Investigation of work-related disorders in truck drivers using RULA method," Applied Ergonomics, vol. 34, no. 4, pp. 303-307, 2003.

[17] M. Bovenzi and A. Betta, "Low-back disorders in agricultural tractor drivers exposed to whole-body vibration and postural stress," Applied Ergonomics, vol. 25, no. 4, pp. 231-241, 1994.

[18] J. Hoy, N. Mubarak, S. Nelson et al., "Whole body vibration and posture as risk factors for low back pain among forklift truck drivers," Journal of Sound and Vibration, vol. 284, no. 3-5, pp. 933-946, 2005.
[19] M. Bovenzi, I. Pinto, and N. Stacchini, "Low back pain in port machinery operators," Journal of Sound and Vibration, vol. 253, no. 1, pp. 3-20, 2002.

[20] G. P. Y. Szeto and P. Lam, "Work-related musculoskeletal disorders in urban bus drivers of Hong Kong," Journal of Occupational Rehabilitation, vol. 17, no. 2, pp. 181-198, 2007.

[21] I. Kuorinka, B. Jonsson, A. Kilbom et al., "Standardised Nordic questionnaires for the analysis of musculoskeletal symptoms," Applied Ergonomics, vol. 18, no. 3, pp. 233-237, 1987.

[22] J. O. Crawford, “The Nordic musculoskeletal questionnaire," Occupational Medicine, vol. 57, no. 4, pp. 300-301, 2007.

[23] C. E. Dickinson, K. Campion, A. F. Foster, S. J. Newman, A. M. T. O’Rourke, and P. G. Thomas, "Questionnaire development: an examination of the Nordic Musculoskeletal questionnaire," Applied Ergonomics, vol. 23, no. 3, pp. 197-201, 1992.

[24] J. M. Porter and D. E. Gyi, "The prevalence of musculoskeletal troubles among car drivers," Occupational Medicine, vol. 52, no. 1, pp. 4-12, 2002.

[25] N. J. Mansfield and J. M. Marshall, "Symptoms of musculoskeletal disorders in stage rally drivers and co-drivers," British Journal of Sports Medicine, vol. 35, no. 5, pp. 314-320, 2001.

[26] A. O. Akinpelu, O. O. Oyewole, A. C. Odole, and R. O. Olukoya, "Prevalence of musculoskeletal pain and health seeking behaviour among occupational drivers in Ibadan, Nigeria," African Journal of Biomedical Research, vol. 14, no. 2, pp. 89-94, 2011.

[27] R. J. Gatchel, "Musculoskeletal disorders: primary and secondary interventions," Journal of Electromyography and Kinesiology, vol. 14, no. 1, pp. 161-170, 2004.

[28] M. Miyamoto, S. Konno, Y. Gembun, X. Liu, K. Minami, and H. Ito, "Epidemiological study of low back pain and occupational risk factors among taxi drivers," Industrial Health, vol. 46, no. 2, pp. 112-117, 2008.

[29] O. A. Samuel and L. E. Babajide, "The prevalence of workrelated musculoskeletal disorder among occupational taxicabs drivers in Nigeria," International Journal of Research \& Reviews in Applied Sciences, vol. 11, 2012.

[30] D. Alperovitch-Najenson, Y. Santo, Y. Masharawi, M. KatzLeurer, D. Ushvaev, and L. Kalichman, "Low back pain among professional bus drivers: ergonomic and occupational-psychosocial risk factors," Israel Medical Association Journal, vol. 12, no. 1, pp. 26-31, 2010.

[31] F. J. Penedo and J. R. Dahn, "Exercise and well-being: a review of mental and physical health benefits associated with physical activity," Current Opinion in Psychiatry, vol. 18, no. 2, pp. 189193, 2005.

[32] H. Miranda, E. Viikari-Juntura, R. Martikainen, E.-P. Takala, and H. Riihimäki, "Physical exercise and musculoskeletal pain among forest industry workers," Scandinavian Journal of Medicine \& Science in Sports, vol. 11, no. 4, pp. 239-246, 2001.

[33] T. I. L. Nilsen, A. Holtermann, and P. J. Mork, "Physical exercise, body mass index, and risk of chronic pain in the low back and neck/shoulders: longitudinal data from the Nord-Trøndelag Health Study," American Journal of Epidemiology, vol. 174, no. 3, pp. 267-273, 2011.

[34] R. D'Onise, E. M. Shanahan, T. Gill, and C. L. Hill, "Does leisure time physical activity protect against shoulder pain at work?" Occupational Medicine, vol. 60, no. 5, pp. 383-388, 2010.

[35] H. Miranda, E. Viikari-Juntura, R. Martikainen, E. P. Takala, and H. Riihimäki, "Physical exercise and musculoskeletal pain among forest industry workers," Scandinavian Journal of Medicine \& Science in Sports, vol. 11, pp. 239-246, 2001. 


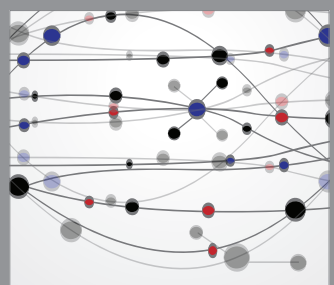

The Scientific World Journal
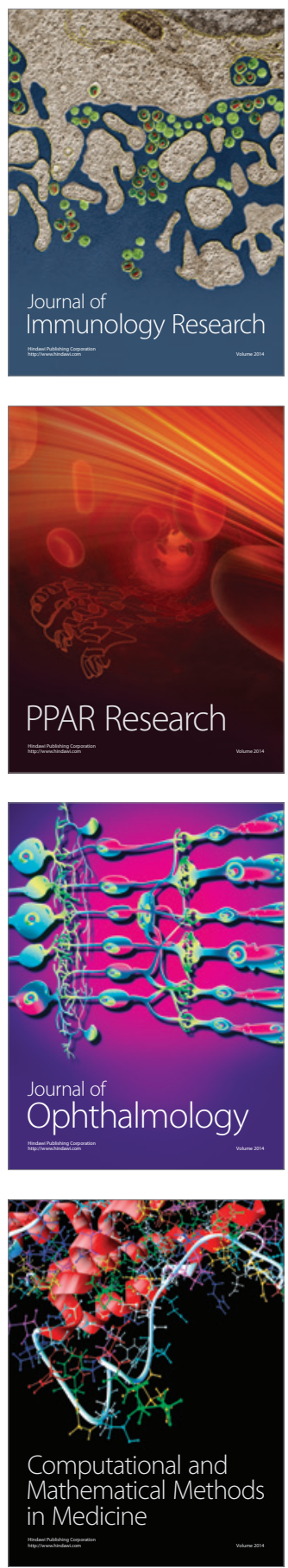

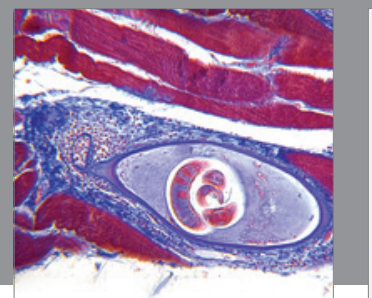

Gastroenterology

Research and Practice
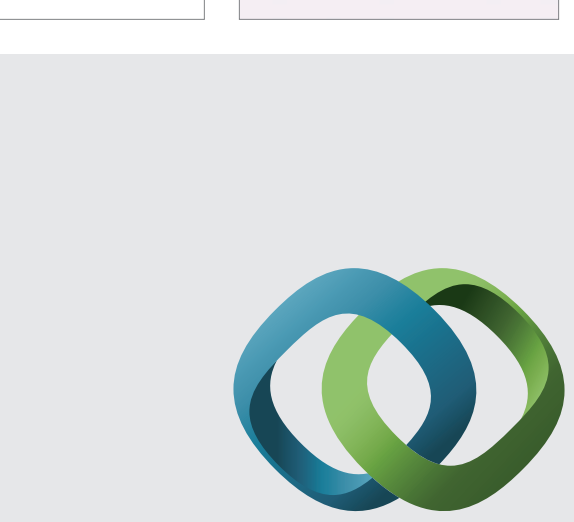

\section{Hindawi}

Submit your manuscripts at

http://www.hindawi.com
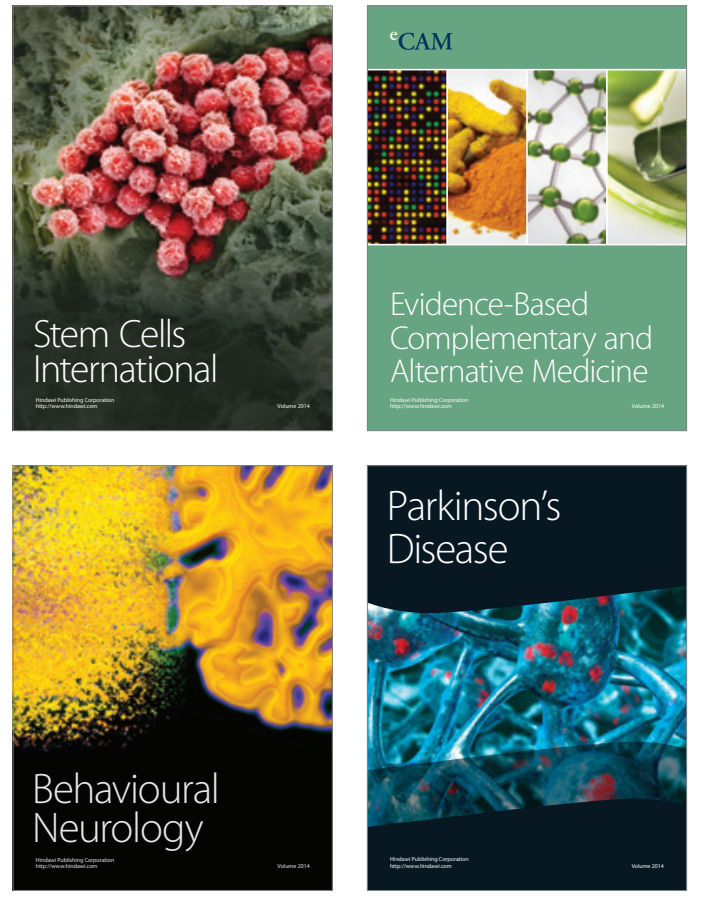
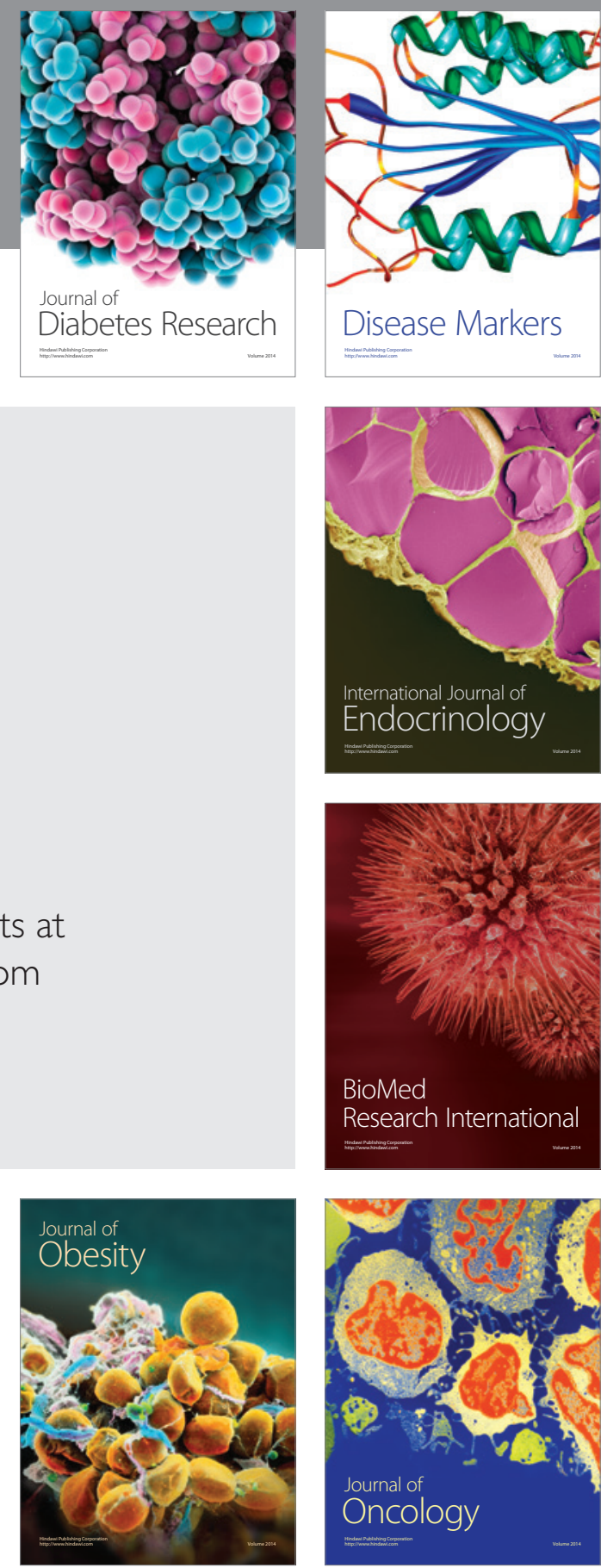

Disease Markers
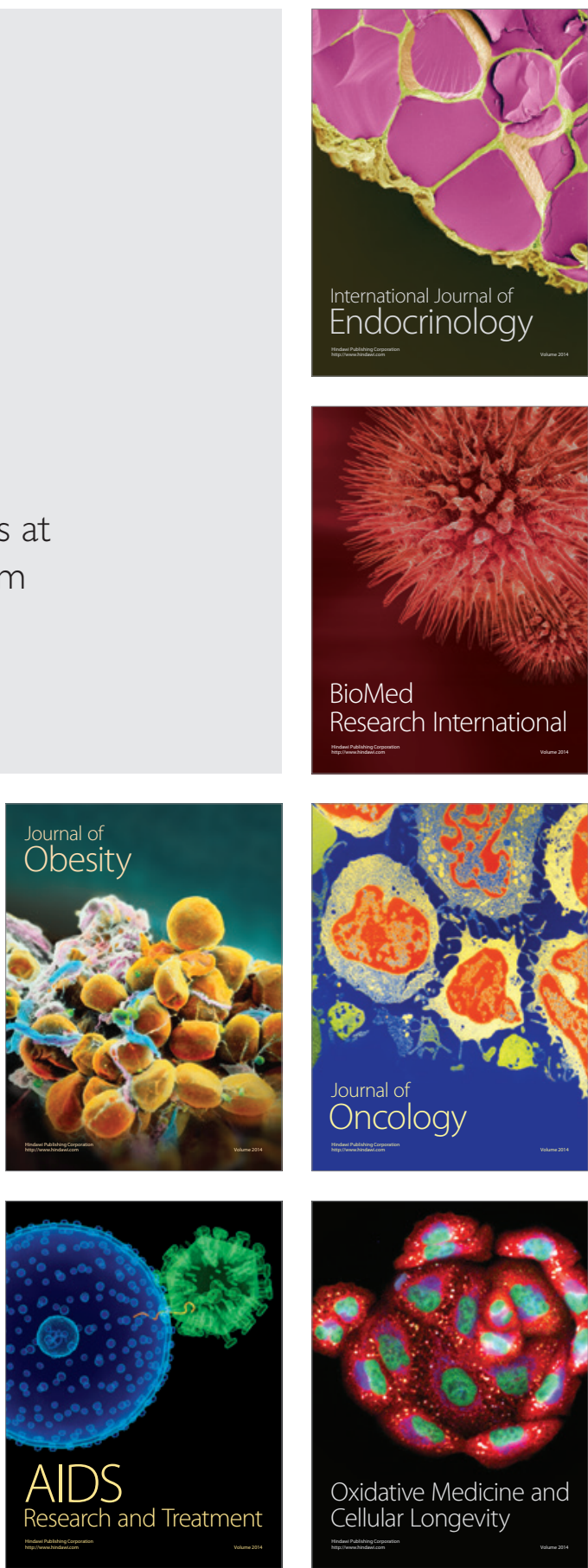